REVIEW

\title{
Interventional cardiac catheterisation in congenital heart disease
}

\author{
R E Andrews, R M R Tulloh
}

Arch Dis Child 2004;89:1168-1173. doi: 10.1136/adc.2003.046532

As a result of recent technological advances, more types of congenital heart disease are amenable to treatment in the cardiac catheter laboratory than ever before.' Improved imaging techniques allow for better selection of patients, and the development of a wide range of devices specifically for use in children means that many patients can avoid surgery altogether, while those with complex congenital heart disease may require fewer or less complex surgical procedures. ${ }^{2}$ This allows for a quicker recovery and a shorter hospital stay, and gives many patients an improved quality of life in the short to medium term. However, the long term outcome for many of the newer forms of intervention is still unknown.

See end of article for authors' affiliations

.....................

Correspondence to: Dr R E Andrews, Department of Congenital Heart Disease, Guy's and St Thomas' NHS Trust, Guy's Hospital, St Thomas' Street, London SEI 9RT, UK; rachel.andrews@ gstt.nhs.uk

Accepted 26 June 2004
$\mathrm{T}$ his article provides a review of the interventional catheter techniques in current use, and their indications. These are broadly divided into "opening" and "closing" procedures, retrieval procedures, and electrophysiological procedures. At the end of the article there is a description of some new techniques which are currently being developed, which may come into more widespread clinical use in the future.

\section{OPENING PROCEDURES}

Balloon dilation procedures

Balloon dilations are performed for a variety of lesions, with aortic and pulmonary stenosis the commonest indications in the developed world. ${ }^{3}$ This includes both the native lesions, and postoperative right ventricular outflow tract obstruction or branch pulmonary stenosis. However, in dence of rheumatic heart disease, balloon dilation is frequently undertaken to relieve mitral stenosis. ${ }^{4}$ The technique may also be used for coarctation of the aorta, so long as the narrowed segment is short, and does not involve the origin of any arising arteries. ${ }^{5}$ In practice this is mainly reserved for recoarctation following previous surgical repair, or for late presentations of coarctation in whom surgery is felt to be too risky, although such cases are increasingly rare.

In any balloon procedure the area to be dilated should be carefully measured, by both two dimensional echocardiography and angiography, to help with selecting a balloon of suitable size and length. Balloons vary in diameter from 1 to $25 \mathrm{~mm}$ and in length from 0.5 to $6 \mathrm{~cm},{ }^{6}$ so that dilation procedures can be carried out in children of any age. The balloon is inserted over a wire, developing countries, which have a high inci- positioned across the area to be dilated, and inflated with radio-opaque contrast. A manometer is connected to the inflation device, to ensure that the pressure applied does not exceed the burst pressure of the balloon. A central waist should be seen on fluoroscopy, which disappears as the balloon is inflated. It is important to complete the inflation and deflation quickly, over just a few seconds, as the circulation will be obstructed while the balloon is inflated.

In the case of valve dilations, relief of stenosis may be at the expense of creating some regurgitation, but this is often well tolerated, especially on the right side of the heart, so long as it is not severe. Other complications of the procedure include balloon rupture, which may cause difficulties with removal, and the possibility of an air embolus, hence the importance of removing bubbles from the contrast mix used for balloon inflation. Generally the procedure is quick, straightforward, and effective.

Although frequently carried out at the bedside rather than in the catheterisation laboratory, balloon atrial septostomy still has an important role in forms of cyanotic heart disease, either where there is inadequate mixing of oxygenated and deoxygenated blood, such as in transposition of the great arteries, or, rarely, where the circulation depends on unrestricted interatrial flow, such as in tricupid atresia, pulmonary atresia with intact ventricular septum, or hypoplastic left heart syndrome. ${ }^{7}$ Echocardiography rather than fluoroscopy is now routinely used to help with positioning of the balloon catheter through the patent foramen ovale into the left atrium prior to inflation. Once inflated, the balloon is pulled back sharply into the right atrium, tearing the atrial septum. Although the procedure is usually straightforward, there is a small risk of inflating the balloon in the left atrial appendage or a pulmonary vein, which would result in cardiac rupture and death unless surgery was immediately available.

\section{Stenting procedures}

Stents are used in an increasing range of situations, and an excellent review of the subject has been written by Okubo and Benson. ${ }^{8} \mathrm{~A}$ wide variety of stents is available, including those which require inflation with an internal balloon to expand them, and those which are selfexpandable once extruded from the sheath. They may be covered, to give them a smoother profile and a solid wall, or uncovered so that the

Abbreviations: ASD, atrial septal defect; PDA, persistent arterial duct; VSD, ventricular septal defect 
mesh of the stent remains exposed. As with balloons, there is a large range of sizes available, so that it is technically possible to stent children of any age. However in practice, stenting is rarely carried out in babies and small children as there is a limited potential for stent expansion, they cannot easily be removed once they are endothelialised, and insertion and expansion of a larger stent through an old one can be technically difficult.

For the purposes of this article, three main indications will be described, namely branch pulmonary artery stenosis, coarctation of the aorta, and arterial duct stenting. These will be dealt with in turn.

- Stenting branch pulmonary arteries: this is rarely carried out for native branch pulmonary stenosis, which is usually mild and regresses with age, but is more frequently used in children who have had previous surgery to their pulmonary arteries. ' Stents may be deployed unilaterally or occasionally bilaterally, and may be placed in series if the narrowed segment is long. There is a small risk of embolisation, following which the stent may be amenable to catheter retrieval, or may require surgical removal. Aspirin is usually given for a period of 3-6 months while the stent becomes endothelialised, to minimise the risk of thrombus formation.

- Stenting of coarctation (fig 1): this procedure is mainly used for older children, either with native coarctation or recoarctation following previous surgery, who are fully grown. ${ }^{10}$ As with balloon dilation, the procedure is only suitable for discrete coarctation. Covered stents may be used as there is less risk of aortic dissection. Frequently the stent will not be dilated to its widest diameter at the time of insertion, again because of the risk of dissection or rupture, but will be progressively dilated during two or two procedures over several months. Embolisation is rare but does occur, and usually requires retrieval by a vascular surgeon. As with stents in the pulmonary tree, aspirin should be given for a period of 3-6 months following insertion.

- Arterial duct stenting: this is occasionally performed in babies with duct dependent systemic blood flow, as for example in hypoplastic left heart syndrome, in centres which offer transplantation as an alternative to staged palliative surgery. In such cases a prolonged period of ductal patency may allow the infant to be bridged to transplant, until an organ becomes available. Stenting for duct dependent pulmonary blood flow is no longer performed in most centres, as in these conditions the duct is usually long and tortuous, making the procedure technically difficult. This led to an unacceptably high mortality rate, due to ductal spasm during the procedure or stenosis subsequently. ${ }^{11}$ The vast majority of babies in this situation undergo a surgical aortopulmonary shunt, such as the modified Blalock-Taussig shunt.

\section{Radiofrequency perforation for pulmonary atresia}

Babies born with pulmonary atresia and an intact ventricular septum depend on patency of the arterial duct for their pulmonary circulation. If the atresia is membranous - that is, there is an imperforate valve, it is possible to burn a hole in the valve with a radiofrequency wire. A balloon is then used to enlarge the hole, to establish antegrade flow to the lungs. This is illustrated in fig 2 . In some cases, a single procedure is all that is required, but if the right ventricle is small, it may be necessary to augment pulmonary blood flow by maintaining ductal patency with prostaglandin $\mathrm{E}$ or performing a modified Blalock-Taussig shunt. ${ }^{12}$ Over subsequent weeks the growth and function of the right ventricle can be assessed, to see whether it will be adequate to support a biventricular circulation. If there is good antegrade flow through the newly opened valve, the duct or shunt may safely be closed.

The major risk with radiofrequency perforation is of perforating the heart, if the wire is not exactly in the right place, but as the wire is very fine, usually this is well tolerated so long as it does not happen repeatedly. To minimise this risk, some operators use a dual approach, aiming the radiofrequency wire from the venous side towards a catheter resting against the distal side of the imperforate valve, inserted from the arterial side via the duct. Very occasionally there may be a significant pericardial effusion, which can lead to tamponade. If there is any concern over possible cardiac perforation, prompt echocardiography should be carried out with a view to insertion of a pericardial drain and/or surgical exploration as appropriate. ${ }^{13}$

\section{CLOSING PROCEDURES}

\section{Persistent arterial duct (PDA)}

Closure of haemodynamically significant ducts in preterm babies who have failed, or are not suitable for, medical treatment should be undertaken surgically. However, in older children (over 1 year), closure of even haemodynamically insignificant ducts has been advocated since the 1980s in order to minimise the risk of bacterial endocarditis. A number of devices have been employed over the years, but the two most commonly used in the UK today are either intravascular coils, such as Cook MReye coils, ${ }^{14}$ or the Amplatzer Duct Occluder. ${ }^{15}$ These are shown in fig 3. Choice of device is influenced by the shape and size of the duct; if it is short and wide, a duct occluder device may be more suitable, but if it is long or tortuous one or more coils, which may be intertwined, may be the best option. The procedure is usually very straightforward and complications are rare, the most significant being device embolisation. If this occurs into the pulmonary tree, an attempt may be made to remove it with a snare, but if it occurs into the systemic circulation, vascular surgery may be required to remove it. Occasionally there may be an episode of haematuria following insertion, due to haemolysis. This is usually short lived as the device becomes endothelialised, and is rarely significant enough to cause anaemia.

\section{Atrial septal defect (ASD)}

Although ASDs do not usually cause such a significant left to right shunt that there is a risk of pulmonary vascular disease, they may cause significant right heart volume overload and in adult life predispose to heart failure and arrhythmias. In addition, patients with ASDs are at risk of a paradoxical embolus should they sustain a deep venous thrombosis. For these reasons, ASDs are usually closed in childhood, ideally before school age. The main criterion for suitability for device closure is that there should be an adequate rim around the defect on which to anchor the device. ${ }^{16}$ Many secundum ASDs are suitable for device closure, but very large defects, or other types of defect such as sinus venosus or partial atrioventricular septal defects (that is, primum ASDs) should be closed surgically. Devices in current use include the Amplatzer Septal Occluder ${ }^{17}$ (fig 4), the Starflex device, ${ }^{18}$ and the Helex device ${ }^{19}$ (fig 5). These come in a variety of sizes, and may be used to close defects up to $38 \mathrm{~mm}$ in diameter. Significant complications of insertion include device malposition or embolisation which may require surgical removal, and erosion against adjacent structures if the device is too large. Transoesophageal echocardiography is routinely used during the procedure to ensure that the defect is suitable for device closure, and to accurately size the defect, to try to minimise these risks. After a few weeks the device becomes 

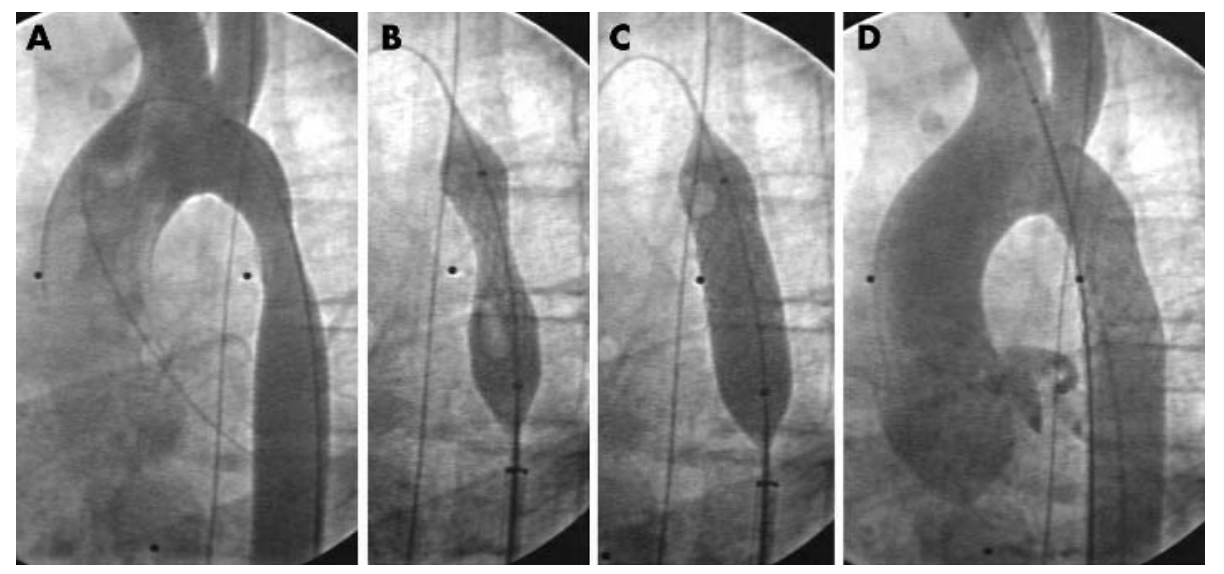

Figure 1 Angiographic pictures of stent insertion for re-coarctation following subclavian flap repair; (A) pre-procedure, (B) stent insertion, (C) stent expansion by inflation of internal balloon, (D) final result.

endothelialised and the risk of complications falls, but aspirin is usually prescribed for 3-6 months to minimise the risk of thrombus formation during this period.

\section{Ventricular septal defect (VSD)}

Compared to either PDAs or ASDs, interventional closure of VSDs is a relatively recent advance. ${ }^{20}$ Initially only midmuscular defects were closed, using a device based on the Amplatzer ASD device, ${ }^{21}$ but very recently a few centres have started to close perimembranous defects, using an asymmetrical device with a narrow subaortic rim..$^{22}$ Although the vast majority of VSDs are still closed surgically, especially if they are large and require closure in infancy, there is an increasing amount of discussion between cardiologists and surgeons as to which moderate sized VSDs are suitable for device occlusion and which should be closed surgically. There is growing support for isolated haemodynamically significant VSDs with good margins being closed in the cardiac catheter laboratory (fig 6). Complications are the same as those for ASD closure, although the risks are somewhat greater as the device is subjected to higher pressure. In addition there is a risk of causing complete heart block, as for surgical VSD closure. Specific risks for subaortic defects include the potential for damage to the aortic valve, or partial obstruction to the left ventricular outflow tract. ${ }^{23}$ Aspirin should be given for a period of 3-6 months until the device becomes endothelialised.

\section{Closure of fenestrations}

Children with only one functioning ventricle undergo a series of palliative operations to gradually separate the pulmonary and systemic circulations. Ultimately a Fontan pattern of circulation is established at around 3-4 years of age, in which the systemic venous blood is directed straight to the lungs by anastomosis of the vena cavae to the pulmonary arteries, so that the ventricle can act solely as the systemic pump. Often a fenestration is created between the inferior vena caval pathway and the body of the right atrium, to allow decompression to the systemic circuit. In the longer term there may be a significant right to left shunt through such
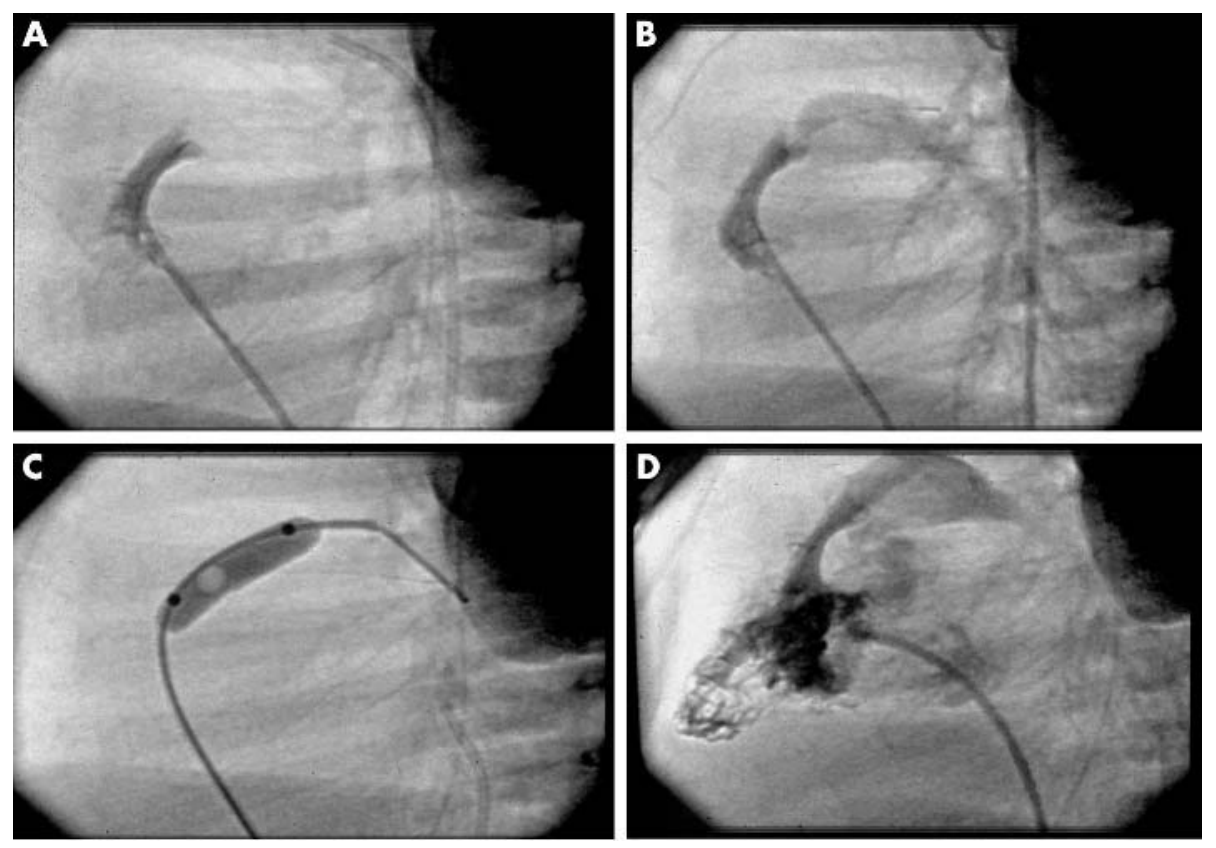

Figure 2 Angiographic pictures of radiofrequency perforation for pulmonary atresia; (A) catheter against imperforate valve (lateral projection), (B) radiofrequency wire across valve, (C) balloon dilation of valve perforation, (D) antegrade flow established. 


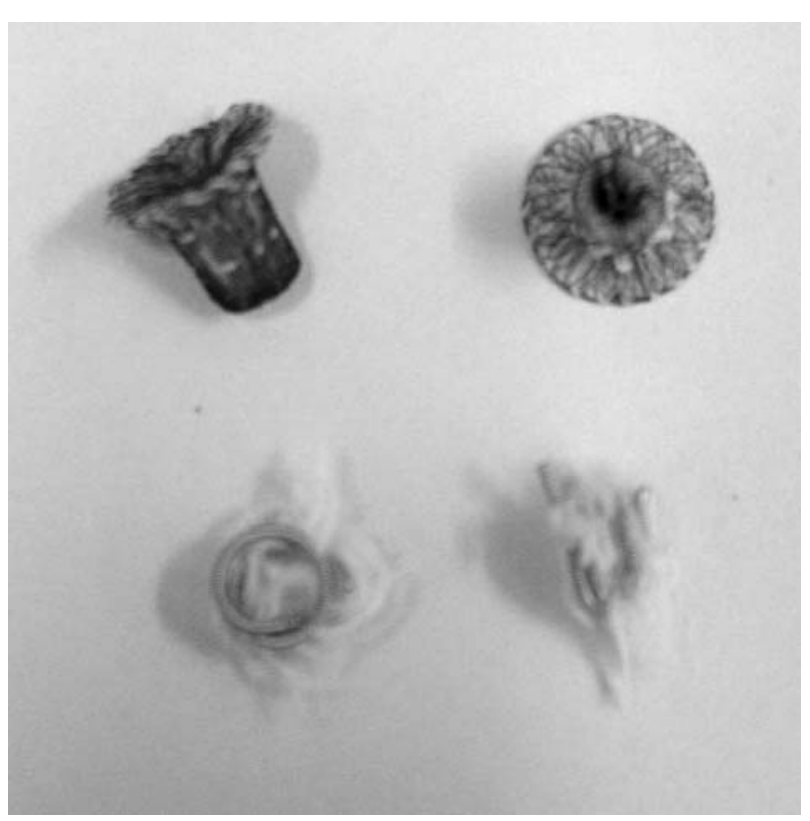

Figure 3 Devices for duct occlusion: a pair of Amplatzer Ductocclude devices, and a pair of Cook MReye coils.

fenestrations, causing desaturation. These fenestrations are often amenable to closure in the cardiac catheter laboratory, using the same type of devices that would be used to close an ASD. ${ }^{24}$ Many of these children are already anticoagulated with warfarin, or are on low dose aspirin, but if they are not, aspirin should be prescribed for a minimum of six months following the procedure.

\section{Embolisation of collaterals}

Collateral vessels occur in a wide variety of conditions, including pulmonary atresia with VSD, scimitar syndrome, and in hearts undergoing Fontan-type reconstruction. They may be arterial or venous, and may shunt left to right or right to left. As they are often difficult for the surgeon to access, they may be occluded with coils or Duct Occluder devices in the cardiac catheter laboratory. ${ }^{25}$

\section{RETRIEVAL PROCEDURES}

A number of ready-made retrieval devices are available, including snares, baskets, and forceps, to permit the retrieval of embolised devices or lines, but their use is limited in children because the vascular sheath size required may be too big. However, "home made" snares fashioned out of guidewires designed for other procedures may be very effective, and allow retrieval of embolised line fragments, even in very small babies. ${ }^{26}$

\section{RADIOFREQUENCY ABLATION PROCEDURES}

The development of radiofrequency ablation has transformed the management of many tachyarrhythmias in middle and later childhood. Previously, vagal manoeuvres, drugs, and DC cardioversion were the only available treatments, none of which were curative. However with radiofrequency ablation, many children can be completely cured. ${ }^{27}$ With the help of intracardiac electrodes recording an ECG from key points of the conduction system, the electrophysiologist can map out the aberrant conduction pathway, and then apply a high frequency low energy electric current via an intracardiac catheter to the area where it originates. This destroys the cells over this very small area, enough to prevent the aberrant rhythm restarting, but not enough to damage the cardiac function or to perforate the heart. The main drawback of the

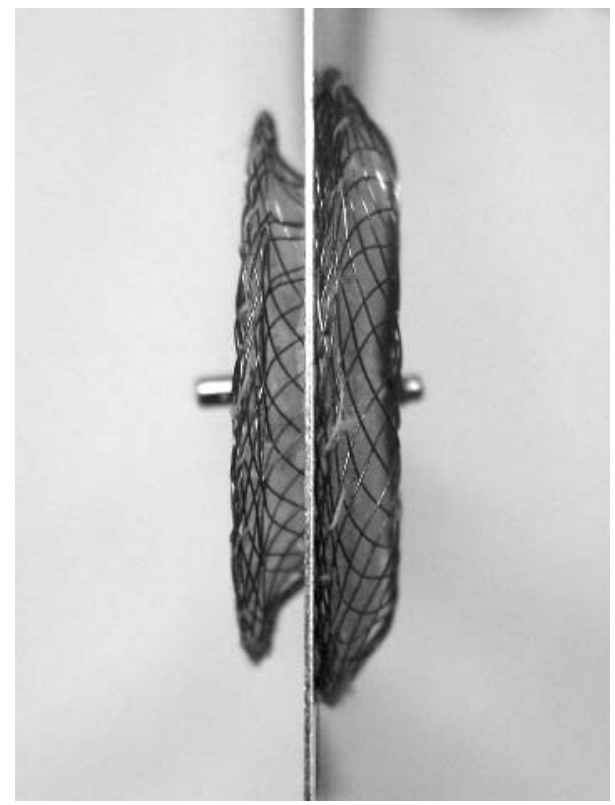

Figure 4 An Amplatzer Septal Occluder for closure of atrial septal defects.

procedure is that mapping the pathway can take a long time, particularly if it originates in the left atrium, when a transseptal puncture is required to access it. This may mean anaesthesia for several hours, and sometimes two procedures may be required. Occasionally the burn may only stun the myocardium, so that the arrhythmia returns. There is also a small risk of causing complete heart block, particularly if the pathway is close to the atrioventricular node. However the majority of procedures are successful, and permanently restore a normal conduction pattern.

\section{RECENT DEVELOPMENTS}

The range of devices available to paediatric cardiologists is ever increasing, as is the range of conditions which are amenable to catheter intervention. A wide ranging review of future developments is beyond the scope of this article, but is

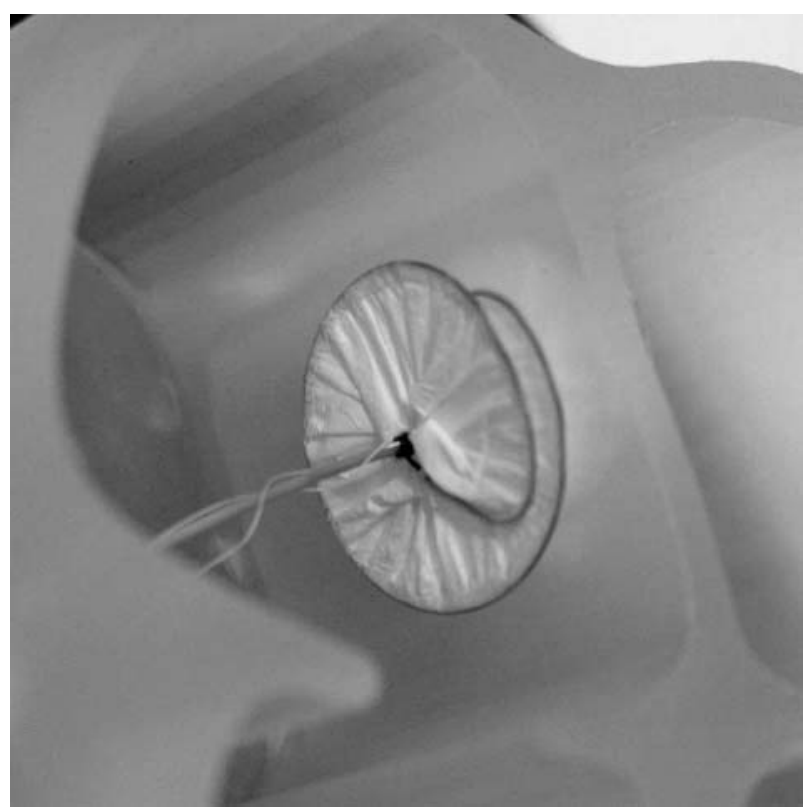

Figure 5 A Helex device for closure of atrial septal defects. 

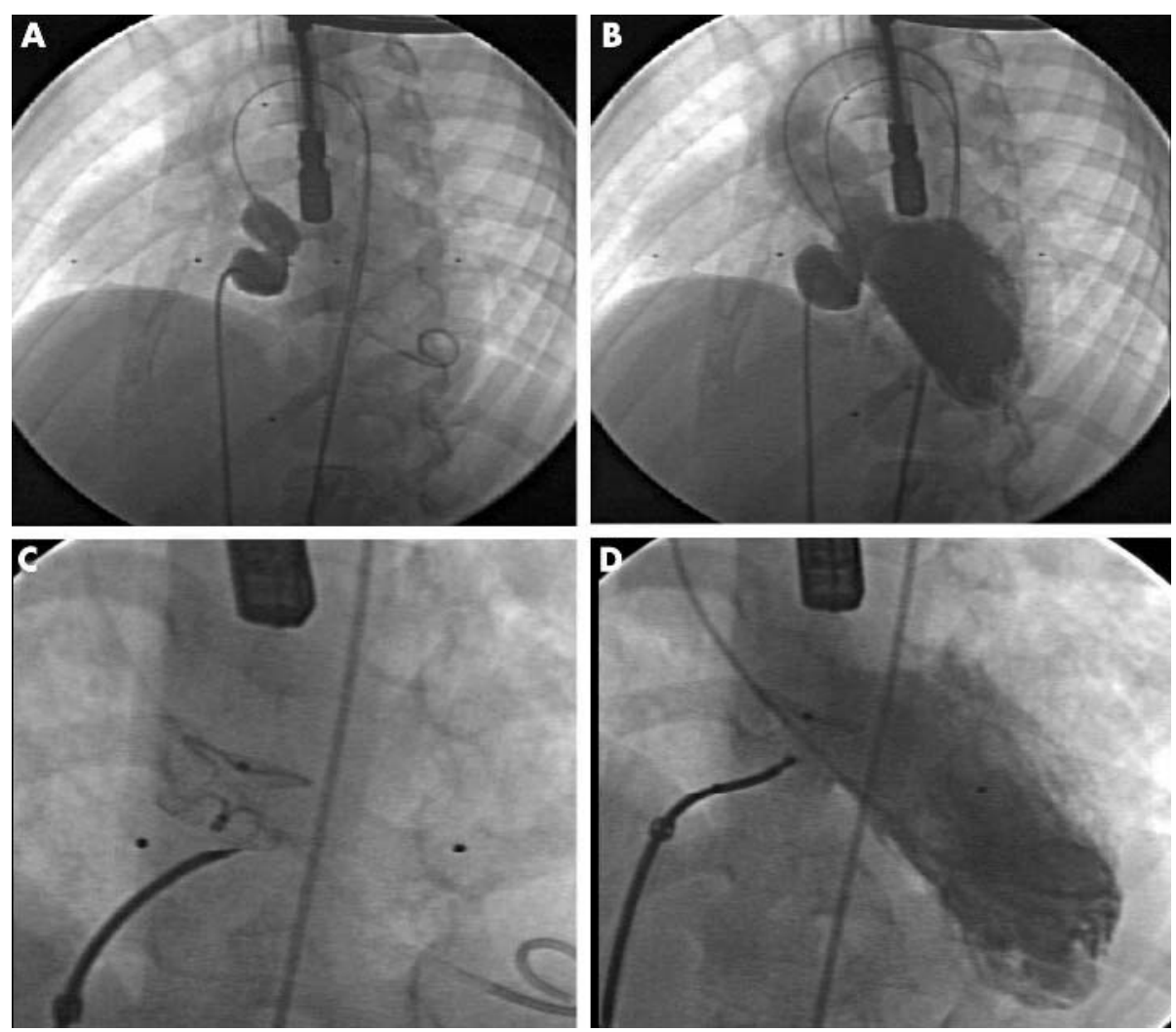

Figure 6 Angiographic pictures of device occlusion of a VSD; $(A)+(B)$ balloon sizing of the defect, $(C)+(D)$ deployment of the device.

provided by Levi et al in Current Opinion in Cardiology. ${ }^{28}$ However, two exciting developments are taking place in the UK, and deserve special mention here. The first is the recent invention of implantable pulmonary valves, which are bovine jugular valves mounted in a balloon expandable stent, ${ }^{29}$ as shown in fig 7. Originally developed in Paris, these are now undergoing trials in London in older children and young adults who have surgically implanted right ventricle to pulmonary artery conduits which have become severely regurgitant, either de novo or as a result of stenting. Insertion of a valve alleviates the regurgitation, reducing the volume load on the right ventricle, and avoids the need for a further major surgical procedure. Animal trials are underway for the aortic equivalent, for treatment of severe aortic regurgitation. ${ }^{30}$

The second is the development of cardiac catheterisation using magnetic resonance imaging (MRI). For a number of years MRI has been an important mode of diagnostic imaging used by paediatric cardiologists. More recently, as noninvasive quantification of flows and shunts has become possible, MRI scans have replaced the majority of diagnostic catheterisation procedures in many units. Work is currently underway to develop MR compatible catheters and devices, such that interventional catheters can be carried out under MR imaging rather than traditional fluoroscopy. ${ }^{31}$ This has great potential benefits in terms of radiation reduction, particularly for children undergoing multiple procedures.

\section{CONCLUSIONS}

The development of an increasingly wide range of interventional devices in a variety of sizes has led to a significant increase in the number of conditions which are now amenable to treatment in the cardiac catheter laboratory. While this approach has considerable benefits over surgery in the short to medium term, it is important to be aware that

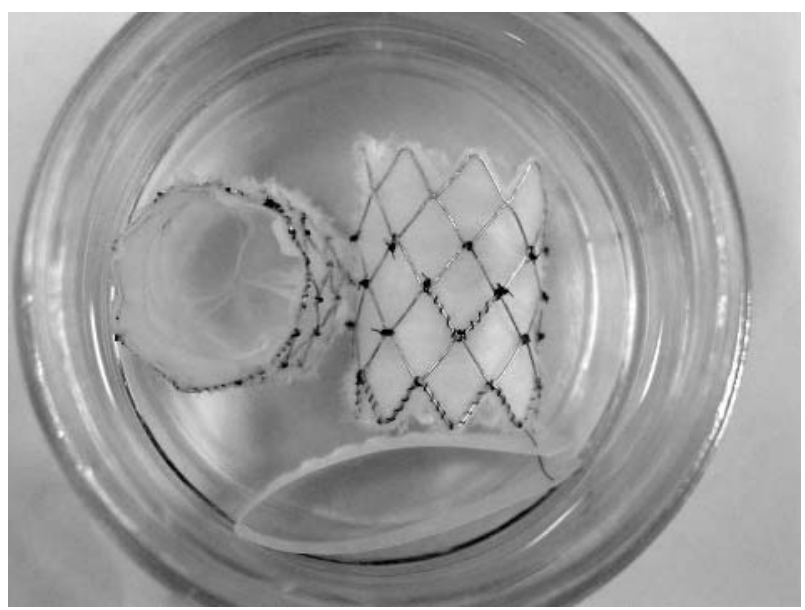

Figure 7 A pair of implantable pulmonary valved stents. The fine tissue of a closed valve is shown in the device on the left.

the long term outcome of many of these interventions is still unknown, and little data is available comparing the results of interventional treatment with surgery. Even where there is some data available, such as for VSD closure (which currently has a higher complication rate post-intervention), many would argue that because interventional VSD closure is a relatively new technique, there is still a learning curve associated with it, and the current rate of complications is likely to fall.

When trying to decide which approach is right for a particular child, a number of practical factors will influence the decision. These include the age of the child (for example, native coarctation in a young child is better treated 
surgically), whether there is one or more lesion requiring attention (multiple problems usually require surgery), where the lesion is (if there is distal branch pulmonary stenosis the surgeon may not be able to reach it easily), and what local expertise is available (particularly relevant with more recent innovations). If there is a choice of approach, the family should be informed of the advantages and disadvantages of each, and their preferences taken into account.

As in other branches of medicine, many paediatric cardiologists are becoming increasingly subspecialised, and most units now have one or more dedicated interventionalists, who are becoming increasingly skilled. However, as yet there are no guidelines available to specify the numbers and types of procedures which should be performed by interventionalists in order to maintain their skills. As the number of cases being diverted from the operating theatre to the cardiac catheter laboratory increases, and the medical profession is required to be ever more accountable for its results, hopefully such guidelines will be available soon.

\section{ACKNOWLEDGEMENTS}

The authors wish to extend their thanks to Dr David Mabin, Consultant Paediatrician, for his help in preparation of this manuscript, and to Prof. Philipp Bonhoeffer and Mr Hal Burnett for their help with the illustrations.

\section{Authors' affiliations}

R E Andrews, R M R Tulloh, Department of Congenital Heart Disease, Guy's and St Thomas' Hospital, London, UK

\section{REFERENCES}

1 Qureshi SA, Redington AN, Wren C, et al. Recommendations of the British Paediatric Cardiac Association for therapeutic cardiac catheterisation in congenital cardiac disease. Cardiol Young 2000;10:649-67.

2 Waight DJ, Hijazi ZM. Pediatric interventional cardiology: the cardiologist's role and relationship with pediatric cardiothoracic surgery. Adv Card Surg 2001;13:143-67.

3 Echigo S. Balloon valvuloplasty for congenital heart disease: immediate to long-term results of a multi-institutional study. Pediatr Int 2001;43:542-7.

4 Bonhoeffer P, Esteves C, Casal U, et al. Percutaneous mitral valve dilatation with the Multi-Track System. Catheter Cardiovasc Interv 1999;48:178-83.

5 Hornung TS, Benson LN, McLaughlin PR. Interventions for aortic coarctation. Cardiol Rev 2002; 10:139-48.

6 Lock JE, Keane JF, Perry SB. Diagnostic and interventional catheterization in congenital heart disease, 2nd edn. Boston, Dordrecht, London: Kluwer Academic Publishers, 2000:124.

7 Zellers TM, Dixon K, Moake L. Bedside balloon atrial septostomy is safe, efficacious, and cost effective compared with septostomy performed in the cardiac catheterisation laboratory. Am J Cardiol 2002;89:613-15.
8 Okubo M, Benson LN. Intravascular and intracardiac stents used in congenital heart disease. Curr Opin Cardiol 2001; 16:84-91.

9 Trivedi KR, Benson LN. Interventional strategies in the management of peripheral pulmonary artery stenosis. J Interv Cardiol 2003;16:171-88.

10 Duke C, Qureshi SA. Aortic coarctation and recoarctation: to stent or not to stent? J Interv Cardiol 2001; 14:283-98.

11 Ruiz CE, Bailey LL. Stenting the ductus arteriosus [Editorial]. Circulation 1999:99:2608-9.

12 Agnoletti G, Piechaud JF, Bonhoeffer P, et al. Perforation of the atretic pulmonary valve. Long-term follow up. J Am Coll Cardiol 2003;41:1399-403.

13 Ovaert C, Qureshi SA, Rosenthal E, et al. Growth of the right ventricle after successful transcatheter pulmonary valvotomy in neonates and infants with pulmonary atresia and intact ventricular septum. J Thorac Cardiovasc Surg 1998; 115:1055-62.

14 Magee AG, Huggon IC, Seed PT. Transcatheter coil occlusion of the arterial duct; results of the European registry. Eur Heart J 2001 22:1768-9.

15 Waight DJ, Cao QL, Hijazi ZM. Transcatheter closure of patent ductus arteriosus using the Ampltzer Duct Occluder. Curr Interv Cardiol Rep $2001 ; 3: 263-7$.

16 Qureshi SA. Selection of patients with secundum atrial septal defects for transcatheter device closure. Eur Heart J 2000;21:573-81.

17 Fischer G, Stieh J, Uebing A, et al. Experience with transcatheter closure of secundum atrial septal defects using the Amplatzer septal occluder: a single centre study in 236 consecutive patients. Heart 2003;8992:199-204.

18 Carminati M, Giusti S, Hausdorf G, et al. A European multicentric experience using the CardioSEal and Starflex double umbrella devices to close interatrial communications holes within the oval fossa. Cardiol Young 2000; 10:519-26.

19 Lopez L, Ventura R, Welch EM, et al. Echocardiographic considerations during deployment of the Helex septal occluder for closure of atrial septa defects. Cardiol Young 2003;13:290-8.

20 Hijazi ZM. Device closure of ventricular septal defects. Catheter Cardiovasc Interv 2003;60:107-14.

21 Chessa M, Carminati M, Cao QL, et al. Transcatheter closure of congenital and acquired muscular ventricular septal defects using the Amplatzer device. $J$ Invasive Cardiol 2002;14:322-7.

22 Bass JL, Kalra GS, Arora R, et al. Initial human experience with the Amplatzer perimembranous ventricular septal occluder device. Catheter Cardiovasc Interv 2003;58:238-45.

23 Pedra CAC, Pedra SRF, Esteves C, et al. Percutaneous closure of perimembranous ventricular septal defects with the Amplatzer device: technical and morphological considerations. Catheter Cardiovasc Interv 2004:61:403-10

24 Hijazi ZM. Extracardiac fenestrated Fontan operation: to close or not to close the fenestration? Catheter Cardiovasc Interv 2001;54:88-92.

25 Beckman RH, Shim D, Lloyd TR. Embolization therapy in pediatric cardiology. J Interv Cardiol 1995;8:543-56.

26 Andrews RE, Tulloh RMR, Rigby ML. Percutaneous retrieval of central venous catheter fragments. Arch Dis Child 2002;87:149-50.

27 Wren C. Catheter ablation in paediatric arrhythmias. Arch Dis Child 1999;81:102-4.

28 Levi DS, Alejos JC, Moore JW. Future of interventional cardiology in pediatrics. Curr Opin Cardiol 2003;18:79-90.

29 Bonhoeffer P, Boudjemline Y, Qureshi SA, et al. Percutaneous insertion of the pulmonary valve. J Am Coll Cardiol 2002;39:1664-9.

30 Boudjemline $Y$, Bonhoeffer P. Steps towards percutaneous aortic valve replacement. Circulation 2002;105:775-8.

31 Razavi R, Hill DL, Keevil SF, et al. Cardiac catheterization guided by MRI in children and adults with congenital heart disease. Lancet 2003;362:1877-82. 